\title{
Drawing and labelling New ways of answering questions on the Assessment Resource Banks
}

\section{JONATHAN FISHER}

\section{Introduction}

The Assessment Resource Banks (ARBs) offer an innovative space to explore how responsive assessment for learning can work off- and online with Aotearoa New Zealand teaching and learning situations. Since 2003, ARBs have been designed to support formative assessment in the classroom. In 2014, work began to redevelop a number of existing pencil-and-paper resources to interactive tasks that could be completed by students online (Joyce \& Fisher, 2014). Now, in 2021, over half the 2,850 resources can be completed online, as well as downloaded as pencil-and-paper tasks. Approximately one-third of the online-interactive tasks can be completely auto-marked by the website.

Many online-interactive assessment tasks use multiple choice or typing in short or long answers. ARB resource developers were also keen to find other ways for students to respond, with the aim of making the online experience more accessible, interactive, and engaging for students. Drag-and-drop and hotspot ways of responding begin to meet this challenge. However, as we redeveloped a number of pencil-and-paper resources to online, we wanted to provide less-constrained ways for students to express their thinking. While students responding online might be able to write to "explain" a thing, they couldn't "show their working" or "draw a ..." without a new way to respond.
As a result, we started exploring ways that students could "show" or "draw" using a drawing tool panel.

\section{Drawing and labelling online}

The drawing/labelling question type provides a way for students to express their thinking or learning when answering certain online assessment tasks. It is important to emphasise that drawing online is different from drawing on paper. It is a particular online skill that may well need to be taught beforehand to ensure it isn't a barrier to the assessment focus of the task. Figure 1 shows the tool panel that students need to learn to use.

Students can select a pencil, an eraser, a line, a shape, a text box (for labelling) or a polygon. They move shapes around, choose colours for line or fill, undo or redo, and zoom in or out, or clear the panel. They can also make the line dashed, or an arrow, or adjust the line thickness.

When a student completes an online drawing assessment, their results will illustrate what they know about the learning area and their level of proficiency with an online drawing tool to construct a basic drawing or a labelled diagram. Such resources can clearly support the development of students' digital fluency. Learning to draw online is a key digital skill and at some stage may help students develop interest for future digital graphic creation.

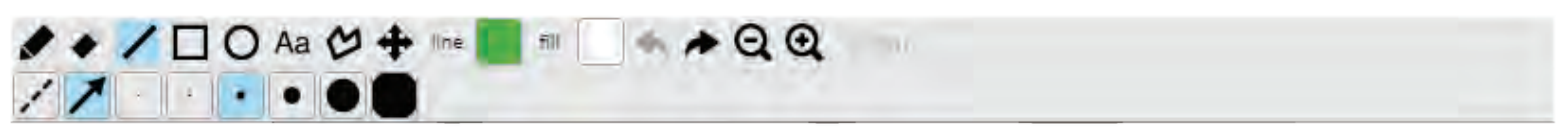


The medium of drawing, and what drawing experiences students are familiar with, will need to be taken into consideration when reviewing student responses. For example, drawing with a mouse can be more difficult than drawing on an iPad with a finger, which can, in turn, be more difficult than drawing on paper with a pencil. You will also need to consider the time frame given for students to complete the task. For example, drawing a line to show symmetry may require a few seconds, labelling a diagram: several minutes, drawing an intricate detailed diagram might take half an hour, or a detailed freehand diagram might require a stylus and might not be a reasonable expectation with a computer mouse.

Like all online-interactive tasks, drawing and labelling tasks can be completed online across a range of devices: iPads, Macs, PC laptops, and Android devices. This new question type cannot be auto-marked by the website, but results can be viewed in the teacher-account results area. Resources with drawing/labelling questions can also be downloaded and completed with pencil and paper.

\section{Some examples of items that use the drawing tool}

Altogether, over 100 resources have been redeveloped to enable students to answer by drawing or labelling online, as well as by pencil and paper.

\section{Drawing/labelling science resources}

Drawing and labelling questions can be especially useful in science for drawing and labelling diagrams. Some examples of science resources are:

- The water cycle ${ }^{\mathrm{r}}$ and Solar eclipse $\mathrm{e}^{2}$ (complete or mark on a diagram)

- What's in the garden, Living on a dairy farm², and What lives in our waterways ${ }^{4}$ (draw and label to add to a sketch)

- Dissolving sugar ${ }^{5}$, The disappearing puddle ${ }^{6}$, and Inside the Earth ${ }^{7}$ (draw and label a diagram from the beginning)

\section{Drawing/labelling mathematics resources}

There are many examples of resources that use the drawing/ labelling question type that ask students to draw a range of responses; from drawing a line (Mirrors and symmetry ${ }^{8}$, Draw a line ${ }^{9}$ ), to drawing a simple shape (Reflecting shapes ${ }^{10}$, Fitting together ${ }^{11}$ ) or a number of shapes (Tessellating patterns ${ }^{12}$ ). Other tasks may require more drawing skill, drawing complex shapes or reflections (Area of shapes ${ }^{13}$, Reflecting figures ${ }^{14}$, Reflecting shapes III $^{15}$ ). Some tasks require a student to continue a repeating pattern (Transforming patterns III' ${ }^{16}$, Transforming patterns IV ${ }^{17}$ ).

\section{Drawing/labelling English resources}

Drawing/labelling questions can also be used in listening comprehension resources. For example, the resources, The $\operatorname{robot}^{18}$ (see Figure 2) and Sea creature ${ }^{19}$, ask students to listen to a description of strange creatures and draw them on the web page. Further resources, Finding your way ${ }^{20}$ and Listen and follow ${ }^{21}$ ask students to listen and then draw pathways on maps using the online drawing tool.

\section{Assessment online including its future potential}

Online assessment has some clear benefits. However, it is a different experience from using pencil and paper and comes with different learning affordances. Some of the key benefits of online assessment (on ARBs) are:

- interactivity between the device and the learner enabled by web technologies

- delivery of assessments through a web platform

- functionality for teachers to view student responses realtime

- location to store evidence of student learning

- assessment availability can be scaled up by scaling up the ARB web server

- piloting and trialling can be run online and results can be analysed in real-time

- publication costs are essentially the website and bandwidth

- maintenance and updating is centralised on the website and doesn't require print reruns.

While recognising the pros of online web technology, it is also important to acknowledge cons, such as it can be hard to express learning or thinking on a device, and equity issues related to: access to devices; access to internet; and access to enriching learning experiences with connected digital devices. The implications of whether online assessment might benefit some learners over others need to be considered. Still, the formative purposes of ARB resources mean that ARBs intend to focus on supporting individual student's learning ideas.

While an online device is a tool with great potential, a pencil and a piece of paper are still powerful technologies to freely express a wide
FIGURE 2. ONLINE DRAWING FROM THE RESOURCE, THE ROBOT

Listen carefully to the description of the strange robotic creature and draw it in the box below. You can start the drawing as soon as you hear the details.

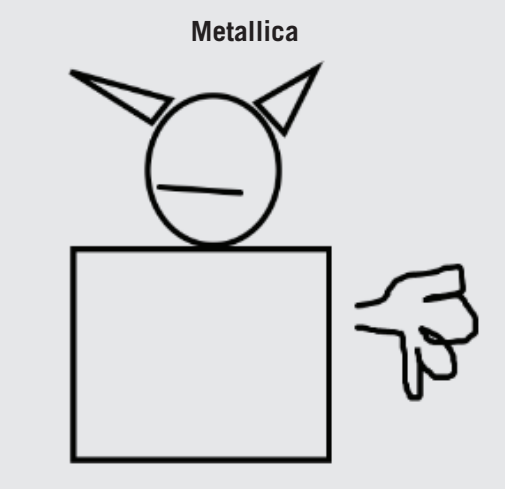


range of thoughts about knowledge and learning. They are accessible, portable, and don't require connection to greater technological infrastructures. ARBs have long catered for such pencil-and-paper assessment experiences. Ultimately, teachers choose the type of assessment resource and the medium that best suits the needs of their learners.

There is also nothing stopping students working in a hybrid fashion with off- and online. For example, students could be answering an online assessment while making notes or drawing with a pad and pencil, or students could work with their peers and then swap over. The resources What shape am I?22 and Describing $\operatorname{dog} s^{23}$ ask students to work with a peer.

\section{Smartphones}

Some of work on the horizon for ARBs involves running assessment tasks on smartphones. Currently, ARBs work across a wide range of devices and operating systems, and we are looking at enabling assessment resources (as well as wider NZCER assessments) to work on Android and iPhone smartphones. We are also redeveloping a number of listening comprehension tasks to run online with audio recording of the main text.

\section{Text-to-speech and speech-to-text}

Also on the horizon is better text-to-speech audio for assessment resources. Currently, the texts for many resources can also be heard through an automated audio library. However, this technology relies upon an opensource development, and, unsurprisingly, the pronunciation of words, particularly the New Zealand accent and Māori kupu, can be problematic. The ARB team is also looking at browser-based audio recording alongside speech-to-text to explore future oral-language assessment for speaking. Using this technology, students could record their speaking (conversation, discussion, explanation, dissertation, etc.) and teachers could both hear the recording and view a transcript. For example, the resource, The monarch: Chrysalis to butterfly ${ }^{24}$, could use this feature by students saying their observations out loud as they watch the video of the life stages of a monarch butterfly.

\section{ARBs are one useful tool in your assessment kete}

ARBs are a freely available online repository of formative assessment tasks that link to The New Zealand Curriculum (Ministry of Education, 2007). They have the potential to support flexible learning situations, wherever the learning takes place. The best way to explore some of the recent innovations might be to go to the website, use a keyword like "draw", and have a look at this drawing and labelling question type in action.
As a part of our work, ARB resource developers seek out new ideas and technologies for doing formative assessment online. While creating these resources, we look to cater for various enablers and barriers for online assessment for learning. There are so many interactive and engaging ways to elicit student thinking, not the least talking to them. Drawing and labelling online might be really helpful, but we recognise that it is just one way to explore student thinking. Task selection should be based upon the learning needs of the learner, not the novelty of a web technology.

\section{Notes}

I. https://arbs.nzcer.org.nz/node/6605

2. https://arbs.nzcer.org.nz/resources/solar-eclipse

3. https://arbs.nzcer.org.nz/resources/living-dairy-farm

4. https://arbs.nzcer.org.nz/resources/what-lives-ourwaterways

5. https://arbs.nzcer.org.nz/node/6723

6. https://arbs.nzcer.org.nz/node/6722

7. https://arbs.nzcer.org.nz/resources/inside-earth

8. https://arbs.nzcer.org.nz/node/ 4848

9. https://arbs.nzcer.org.nz/node/4980

Io. https://arbs.nzcer.org.nz/node/4897

II. https://arbs.nzcer.org.nz/node/4830

I2. https://arbs.nzcer.org.nz/node/4855

I3. https://arbs.nzcer.org.nz/node/4646

I4. https://arbs.nzcer.org.nz/node/490I

I5. https://arbs.nzcer.org.nz/node/48I9

I6. https://arbs.nzcer.org.nz/node/4856

I7. https://arbs.nzcer.org.nz/node/4885

I8. https://arbs.nzcer.org.nz/node/3613

I9. https://arbs.nzcer.org.nz/node/36I4

2I. https://arbs.nzcer.org.nz/node/3676

2I. https://arbs.nzcer.org.nz/resources/listen-and-follow

22. https://arbs.nzcer.org.nz/resources/what-shape-am-i

23. https://arbs.nzcer.org.nz/resources/describing-dogs

24.https://arbs.nzcer.org.nz/resources/monarch-chrysalisbutterfly

\section{References}

Joyce, C., \& Fisher, J. (2014). Assessment for learning, online tasks, and the new Assessment Resource Banks. Set: Research Information for Teachers, (2), 51-53. https://doi.org/10.18296/ set.0314

Ministry of Education. (2007). The New Zealand curriculum. Learning Media.

Jonathan Fisher is a senior resource developer/researcher at the New Zealand Council for Educational Research.

Email: jonathan.fisher@nzcer.org.nz 